\title{
Workplace Spirituality and Occupation: A Study of Employees in Higher Education Institutions
}

\author{
Aminah $\mathrm{AHMAD}^{1, *}$ and Zoharah OMAR ${ }^{2}$ \\ ${ }^{1}$ Institute for Social Science Studies, Universiti Putra Malaysia \\ 43400 UPM Serdang, Selangor, Malaysia \\ ${ }^{2}$ Faculty of Educational Studies, Universiti Putra Malaysia \\ 43400 UPM Serdang, Selangor, Malaysia \\ ${ }^{*}$ Corresponding author
}

Keywords: Workplace spirituality, Occupation, Higher education institution.

\begin{abstract}
The aim of this paper is to examine workplace spirituality in terms of its dimensions, namely meaningful work, sense of community and allignment of values, among employees in private higher education institutions in Greater Kuala Lumpur, Malaysia. The differences among the spirituality dimensions according to occupation were explored. Data were collected from a sample of 102 employees using self-administered questionnaires. There were no significant mean differences in overall workplace spirituality scores for occupation. Of the three dimensions, meaningful work significantly differed by occupation. Academics reported significantly higher levels of meaningful work than did administrators. Post-hoc analysis of comparison between means for academic and administrator groups indicated a significant difference.
\end{abstract}

\section{Introduction}

Workplace spirituality has been defined as "the recognition that employees have an inner life that nourishes and is nourished by meaningful work that takes place in a community" [1]. An employee is not only concerned about paycheck but meaningful work, and attempts to be a holistic person, connected to his or her co-workers and to the transcendent [2]. Three dimensions of workplace spirituality, "meaningful work" (individual level), "sense of community" (group level) and "alignment with organizational values" (organization level), were identified and measured by Milliman et al. [3].

The importance of sense of community and values at work has been emphasized by Giacalone and Jurkiewicz [4], and they defined workplace spirituality as "a framework of organizational values evidenced in the culture that promotes employees' experience of transcendence through the work process, facilitating their sense of being connected to others in a way that brings feelings of completeness and joy" (p. 13). According to Adams and Csiernik [5]"workplace spirituality involves positively sharing, valuing, caring, respecting, acknowledging and connecting the talents and energies of people in a meaningful goal-directed behavior that enables them to belong, be creative, be personally fulfilled and take ownership in their combined destiny" (p. 43). Another definition was provided by Marques [6] who defined workplace spirituality as "an experience of interconnectedness and trust among those involved in a work process, engendered by individual goodwill, leading to the collective creation of a motivational organizational culture, epitomized by reciprocity and solidarity; and resulting in enhanced overall performance, which is ultimately translated in lasting organizational excellence" (p. 283). There seems to be many definitions of workplace spirituality and 
there is lack of agreement among scholars on an appropriate definition. However, Duchon and Plowman [7] concluded that the elements in most definitions of workplace spirituality were the sense of meaning, purpose as well as connectedness.

Researchers and practitioners now realize that supporting workplace spirituality can to a certain extent help improve employee performance [8] [9]. Several scholars suggest that besides improving performance, spirituality can result in higher productivity, increased problem solving capabilities, better decision making, higher intuitive capabilities, greater creativity and more efficient utilization of resources [10]. A review of previous studies suggests that spirituality experienced by employees at the workplace would motivate them to display organizational citizenship behavior [11].

Researchers have explored different demographic factors that foster spirituality at the workplace. Huma et al. [12] found that a leader's age, education, and experience influence the leader's spiritual behaviors. Houston and Cartwright [13] discovered that employees in public service occupations tend to be more spiritual than those in non-public service occupations, while Sharique et al. [14] found that female athletes were more spiritual than males. However Debats [15], in a study on sources of meaning in life did not find significant associations between meaning in life and age, sex, and educational level. The researcher argued that the search for meaning in life seemed to be a basic human drive and a universal phenomenon that is independent of demographic.

Ecklund and Long [16] found that spirituality varies across occupational groups based on their in-depth interviews with 275 social and natural scientists at 21 top research universities in the United States. The results indicate that spirituality may be linked to characteristics of particular identity statuses of individuals such as occupational groups. Despite the prevalence of previous studies exploring the link between workplace spirituality and demographics of employees, the results were inconclusive, and hence there is still a need to explore differences in workplace spirituality according to occupation.

According to Ecklund and Long [16], researchers who wish to build on their work should ask what specific group characteristic lead to which particular kind of spirituality? In this present study we posed the following research question: Would employees with different occupations differ in terms of their likelihood to experience spirituality at the workplace. To build further on previous work, this present study examined workplace spirituality in terms of meaningful work, sense of community and allignment of values, among employees in private higher education institutions in Greater Kuala Lumpur, Malaysia. The differences among the spirituality dimensions according to occupation were explored.

\section{Methodology}

\section{Sample and Procedure}

The sample consisted of 102 employees with at least three years of experience working at three private higher education institutions in Greater Kuala Lumpur, Malaysia. Data were gathered using self-administered questionnaires through the drop and collect method. 


\section{Measurement}

Workplace spirituality was measured using Spirituality at Work (SAW) scale consisting of 21 items by Milliman et al. [5]. The three dimensions of the scale include meaningful work (6 items), sense of community ( 7 items), and alignment of employee and organizational values (8 items). A sample of item for the meaningful work dimension is "I see a connection between work and social good", the sense of community dimension is "I feel part of a community at work", and the alignment of values dimension is "I feel positive about the values of the organization". Participants were requested to indicate the level of their agreement with statements using response options ranging from "strongly disagree" (1) to "strongly agree" (7).

\section{Analysis of Data}

The construct reliability coefficients of overall workplace spirituality scale and its dimensions were calculated. Means and standard deviations were computed to describe the sample and study variables. ANOVA was conducted to examine the differences in means of the total workplace spirituality scores, and the scores for the three dimensions according to occupation. Bonferroni post hoc analysis was conducted to test the pairwise comparison of means.

\section{Results and Discussion}

The demographic characteristics of the respondents are presented in Table 1. The respondents ( 29 males, 73 females) had an average age of 37 years. About two-thirds had earned a diploma or bachelor degree. Almost a third were academics, about half were administrators while about a quarter were in the clerical group.

Table 1. Demographic characteristics of respondents $(n=102)$

\begin{tabular}{|l|l|c|c|}
\hline Variable & Frequency & $\%$ \\
\hline \multirow{5}{*}{ Age } & $20-29$ & 19 & 18.6 \\
\cline { 2 - 4 } & $30-39$ & 50 & 49.0 \\
\cline { 2 - 4 } & $40-49$ & 23 & 22.5 \\
\cline { 2 - 4 } & $50-59$ & 10 & 9.8 \\
\cline { 2 - 4 } & $M=37.03 ; S D=8.97$ & 29 & 28.4 \\
\hline \multirow{5}{*}{ Gender } & Male & 73 & 71.6 \\
\cline { 2 - 4 } & Female & 12 & 11.8 \\
\hline \multirow{5}{*}{ Education } & High school certificate & 61 & 59.8 \\
\cline { 2 - 4 } & Diploma /Bachelor degree & 29 & 28.4 \\
\cline { 2 - 4 } & Master/Ph.D. & 31 & 30.4 \\
\hline \multirow{5}{*}{ Occupation } & Academic & 47 & 46.1 \\
\cline { 2 - 4 } & Administrator & 24 & 23.5 \\
\cline { 2 - 4 } & Clerk & & \multicolumn{2}{|c|}{} \\
\hline
\end{tabular}

Means, standard deviations, number of items for measuring meaningful work, sense of community, alignment of values and the overall workplace spirituality, as well as their reliability coefficients are shown in Table 2. The means for overall workplace spirituality as well as the three dimensions were relatively high. The employees have a sense of purpose in their work where they express their total selves, including their spiritual selves. They are provided with opportunities to perform meaningful work with a sense of joy as well as personal fulfilment within the context of a caring community. Additionally, they feel positive about the values of their organizations and feel connected to their organizations' goals. 
Table 2. Means, standard deviations, and reliability coefficients for workplace spirituality

\begin{tabular}{|l|c|c|c|c|}
\hline Variable & Mean & SD & No. of item & Reliability \\
\hline Meaningful Work & 5.40 & .935 & 6 & .934 \\
\hline Sense of Community & 5.42 & .807 & 7 & .903 \\
\hline Alignment of Values & 5.09 & 1.007 & 8 & .944 \\
\hline Overall Workplace Spirituality & 5.30 & .842 & 21 & .964 \\
\hline
\end{tabular}

Table 3. Means and standard deviations for workplace spirituality by occupation

\begin{tabular}{|l|c|c|c|c|c|c|c|c|}
\hline \multirow{2}{*}{ Occupation } & \multicolumn{2}{|c|}{ Meaningful work } & \multicolumn{2}{c|}{$\begin{array}{c}\text { Sense of } \\
\text { community }\end{array}$} & \multicolumn{2}{c|}{$\begin{array}{c}\text { Alignment of } \\
\text { values }\end{array}$} & \multicolumn{2}{c|}{$\begin{array}{c}\text { Workplace } \\
\text { spirituality }\end{array}$} \\
\cline { 2 - 10 } & Mean & SD & Mean & SD & Mean & SD & Mean & SD \\
\hline Academic & 5.74 & .828 & 5.62 & .855 & 5.35 & 1.127 & 5.56 & .863 \\
\hline Adminstrator & 5.23 & .932 & 5.29 & .741 & 4.91 & .984 & 5.14 & .802 \\
\hline Clerk & 5.29 & .988 & 5.42 & .848 & 5.09 & .843 & 5.27 & .843 \\
\hline
\end{tabular}

Table 4. ANOVA of workplace spirituality by occupation

\begin{tabular}{|l|l|c|c|c|c|}
\hline Variable & Source of variation & df & MS & F & $\mathrm{p}$ \\
\hline MW & Between groups & 2 & 2.642 & 3.152 & $.047^{*}$ \\
& Within group & 99 & .838 & & \\
& Total & 101 & & & \\
\hline SC & Between groups & 2 & 1.024 & 1.589 & .209 \\
& Within group & 99 & .644 & & \\
& Total & 101 & & & \\
\hline AV & Between groups & 2 & 1.775 & 1.776 & .175 \\
& Within group & 99 & .999 & & \\
& Total & 101 & & & \\
\hline WPS & Between groups & 2 & 1.662 & 2.410 & .095 \\
& Within group & 99 & .690 & & \\
& Total & 101 & & & \\
\hline
\end{tabular}

Note: $\mathrm{MW}=$ meaningful work; $\mathrm{SC}=$ sense of community; $\mathrm{AV}=$ alligment of values;

$\mathrm{WSP}=$ overall workplace spirituality; $* \mathrm{p}<.05$

The academics scored the highest in overall workplace spirituality and in all spirituality dimensions (Table 3). Of the three dimensions, meaningful work significantly differed by occupation (Table 4). Results of post-hoc analysis using the Bonferroni test for comparison between means for academic and administrator groups indicated a significant mean difference of .513 $\pm .212(p<.05)$, with the academic group having a higher score. However, comparisons between means for academic and clerical groups, and administrator and clerical groups were not significant.

The results on differences in meaningful work as a dimension of spirituality according to occupation is in line with those of Ecklund and Long [14] who found that spirituality varies across occupational groups. The results indicate that spirituality may be linked to characteristics of employees such as occupation, and imply that occupation should be considered as a possible variable that needs to be controlled in investigating outcomes of spirituality. Future work on workplace spirituality should examine the phenomenon in terms of its different dimensions rather than the phenomenon as a whole.

\section{Acknowledgement}

This research is financially supported by the Ministry of Education, Malaysia under the Fundamental Research Grant Scheme. 


\section{References}

[1] D.P. Ashmos and D. Duchon, Spirituality at work, Journal of Management Inquiry 9:2 (2000) 134-145

[2] R. Hudson, The question of theoretical foundations for the spirituality at work movement, Journal Management, Spirituality and Religion, 11 (2014) 27-44.

[3] J. Milliman, A.J. Czaplewski, and J. Ferguson, Workplace spirituality and employee work attitudes: An exploratory empirical assessment, Journal of Organizational Change Management, 16:4 (2003) 426-447.

[4] R.A. Giacalone and C.L. Jurkiewicz, Toward a science of workplace spirituality, In: R.A. Giacalone and C.L. Jurkiewicz, eds. Handbook of Workplace Spirituality and Organizational Performance, Armonk: M.E. Sharpe, 3-28, 2003.

[5] D.W. Adams and R. Csiernik, Seeking the lost spirit: Understanding spirituality and restoring it to the workplace, Employee Assistance Quarterly, 17 (2002) 31-44.

[6] J. Marques, HR's crucial role in the establishment of spirituality in the workplace, Journal of American Academy of Business, 7 (2005) 27-31.

[7] D. Duchon and D.A. Plowman, Nurturing the spirit at work: Impact on work unit performance, The Leadership Quarterly, 16 (2005) 807-833.

[8] M.S. James, A.K. Miles and T. Mullins, The interactive effects of spirituality and trait cynicism on citizenship and counterproductive work behaviors. Journal of Management, Spirituality and Religion, 8 (2011) 165-182.

[9] P. Petchsawanga and D. Duchon, Workplace spirituality, meditation, and work performance, Journal of Management, Spirituality and Religion, 9:2 (June 2012) 189208.

[10]E. Weitz, Y. Vardi and O. Setter, Spirituality and organizational misbehavior. Journal of Management, Spirituality and Religion, 9 (2012) 255-281.

[11] Aminah A. and O. Zoharah, Improving organizational citizenship behavior through spirituality and work engagement, American Journal of Applied Sciences, 12:3 (2015) 200-207.

[12] A. Huma and A. Hina, Demographics and spiritual leadership: Empirical Evidence from Pakistan, Business and Management Review, 1:10 (2011) 36-42.

[13] D.J. Houston and K.E. Cartwright, Spirituality and public service, Public Administration Review, 67:1 (2007) 88-102.

[14] M. Sharique, S.T. Murtaza, and S. Sharif, A comparative study of spirituality between male and female sportspersons of Aligarh Muslim University, Aligarh, Golden Research Thoughts, 1:7 (2012) 1-4.

[15] D.L. Debats, Sources of meaning: An investigation of significant commitments in life, Journal of Humanistic Psychology, 39 (1999) 30-57.

[16] E.H. Ecklund and E. Long, Scientists and spirituality, Sociology of Religion, 72:3 (2011) 253-274. 